\title{
Article \\ Chilean Migrants in the Swedish Context from the 1970s until Recently: The Discursive Construction of Their Own Linguistic Trajectories
}

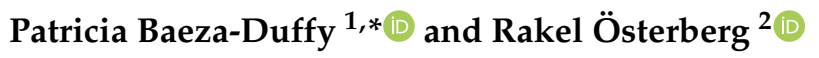 \\ 1 Department of Language Sciences, Pontifical Catholic University of Chile, Av. Vicuña Mackenna 4860, \\ Santiago 7810000, Chile \\ 2 Department of Romance Studies and Classics, Stockholm University, Universitetsvägen 10B, \\ SE-106 91 Stockholm, Sweden; rakel.osterberg@su.se \\ * Correspondence: pmbaeza@uc.cl
}

check for updates

Citation: Baeza-Duffy, Patricia, and Rakel Österberg. 2021. Chilean Migrants in the Swedish Context from the 1970s until Recently: The Discursive Construction of Their Own Linguistic Trajectories. Languages 6: 95. https://doi.org/ 10.3390/languages6020095

Academic Editors: Jaine Beswick and Darren Paffey

Received: 22 January 2021

Accepted: 18 May 2021

Published: 24 May 2021

Publisher's Note: MDPI stays neutral with regard to jurisdictional claims in published maps and institutional affiliations.

Copyright: (c) 2021 by the authors. Licensee MDPI, Basel, Switzerland. This article is an open access article distributed under the terms and conditions of the Creative Commons Attribution (CC BY) license (https:/ / creativecommons.org/licenses/by/ $4.0 /)$.

\begin{abstract}
This study aims to compare the discursive construction of Chilean migrants who arrived in Sweden from the 1970s until recently regarding their own linguistic trajectories at the micro level of social activity, the meso level of sociocultural institutions and communities and the macro level of ideological structures. The analysis of the latter level is based on Critical Discourse Studies, in particular, the strategies of de/legitimisation and the macro strategies of perpetuation or transformation The research questions concern (a) the semiotic resources used in multilingual contexts of action and interaction (at a micro level), (b) expressions of belonging and language identity (at a meso level) (c) and the de/legitimisation of events, processes and social actors in the construction of different ideologies (at a macro level). The method is qualitative and interpretative and is based on critical discourse analysis. The findings showed that the de/legitimisation of policies is associated with access to and acquisition of L2 (Swedish) and maintenance of L1 (Spanish). Well-prepared teachers, the communicative setting of the multicultural language classroom and the linguistic mediators were legitimised, while the process of adaptation and volunteers without sufficient preparation were delegitimised. Societal changes were identified as macro strategies that resulted in the transformation or perpetuation of what was being legitimised or delegitimised.
\end{abstract}

Keywords: Chilean migrants; Swedish context; linguistic trajectories; critical discourse studies; strategies of de/legitimization

\section{Introduction}

Immigration is a social phenomenon that has increased in the past decades in different European countries, such as Sweden and Spain, to just mention a few, as well as in various continents. In search of a better quality of life (Martínez Lirola 2017; Salas et al. 2017), migrants travel to other countries, where pro and anti-migrant voices emerge. In other words, immigration has become a highly politicized topic in recent years, especially in terms of the ideologization of debates and policies (Krzyzanowski et al. 2018).

Sweden has received a number of Chilean migrants, starting with a wave of refugees in 1973 following the coup d'état in Chile and extending until the mid-1990s (Mella 1990). Consequently, Chileans constitute a considerable number of migrants among the other communities in Sweden of Arabic, Bosnian, Kurdish, Eritrean, Farsi, Finnish, Greek, Somalian and Syrian origin (among others). Spanish is the seventh most spoken language in Sweden (Parkvall 2015) and, according to Parada (2018), Chileans constitute the major linguistic community of the Spanish-speaking population in Sweden and are the third largest Chilean population outside Chile.

The first wave of Chilean migrants in the 1970s comprised well-known politicians, syndicate leaders, many of whom came from an academic background. Other reasons for 
migrating, including poverty and family circumstances, became increasingly more significant, particularly in the 1980s (Mella 1990). Although King and Ganuza (2005) carried out research on language identity in young Chileans returning to Parada (2018) conducted more recent studies, there is still a knowledge gap regarding the identity processes that occur in multilingual contexts. Migration from Chile to Sweden took place over an extended period during which Sweden developed into a multilingual society, resulting in changing attitudes and linguistic policies (Donoso et al. forthcoming; Hyltenstam and Österberg 2010).

The aim of the present study is to analyse the linguistic trajectories of Chilean migrants who emigrated to Sweden during different decades from 1970 onwards. These migrants offer the opportunity to study expressions of identity and belonging over time and how the processes of inclusion and exclusion interact with the growing multilingual context and personal linguistic trajectories (Saguy and Kteily 2014; De Fina 2013) in relation to the different policies related to access to and acquisition of a second language (Swedish) and maintenance of the first language (Spanish).

In line with the recent call by The Douglas Fir Group (2016) for transdisciplinary studies of real-world issues and multilingualism, this study aims to merge critical discourse studies-in particular, the strategies of de/legitimisation and the macro strategies for perpetuation or transformation (De Cillia et al. 2015) -with socioculturally orientated theories of language identities and transnational interconnectedness, as described by Thomas and Osment (2019) and Canagarajah (2018).

In addition to the latter theories, expressions of belonging are particularly important and will be analysed according to the concepts of social embeddedness and anchoring (Beswick 2020).

The research questions are as follows:

(a) At a micro level: What semiotic resources are used to describe engagement in multilingual contexts of action and interaction?

(b) At a meso level: What expressions of belonging and language identity are described?

(c) At a macro level: What events, processes and social actors are legitimised and delegitimised in accordance with the ideology of each of the interviewees?

The findings indicate that expert instruction in Swedish as a second language (L2), the communicative setting of the multicultural language classroom, the linguistic mediators, the contact with nature as reinforcing language learning and openness towards multiculturalism are legitimised, while the difficult process of adaptation to society along with teachers, instructors and volunteers without sufficient preparation are delegitimised.

\section{Theoretical Framework}

\subsection{Contextualisation}

The benefits of multilingual repertoires are often questioned in Swedish media and heavily debated at a political level (Hyltenstam and Milani 2012). At the heart of the debate is the question of multilingualism - whether maintaining or abandoning the mother tongue promotes a sense of belonging in a new society. In the debate, linguistic diversity is sometimes described as an obstacle to learning the language of the adopted country, in this case, Swedish (Stroud 2004). The role of language training and mother tongue instruction have been actualised in studies concerning the Scandinavian countries' policies regarding the current global migration to Europe (Emilsson 2015). The debate is often political, as is the case in Denmark (Salö et al. 2018) and also recently in Sweden-and is not always directly based on research of language use. The rhetorical presentation of integration in educational steering documents might also differ from the practice itself (Dahlström 2004).

Swedish language policy has pointed to the benefits of maintaining the mother tongue (SOU 1983; Hyltenstam and Milani 2012). This policy entails a positive view of minority language use, cultural diversity and active bilingualism, in contrast to countries with a language policy of "English only or another language only" (Aktürk-Drake 2018; Philipson 2009). The Swedish ambition to maintain mother tongues is realised by offering specialised courses in mother tongue instruction and Swedish as a second language. Mother tongue 
instruction was introduced in 1977 and was called Home Language Reform (Salö and Karlander 2018), with the aim of developing skills in the first language (L1) while also preparing Sweden for internationalisation and a progressive, multilingual society. According to the Swedish Education Act (Utbildningsdepartementet [Ministry of Education and Research] 2010, p. 800), children are entitled to receive mother tongue instruction for a maximum of 1 hour per week when the language is used at home on a daily basis and the group comprises more than five pupils, except when the language is one of the five minority languages spoken in the country. For further information, see Hyltenstam and Österberg (2010). Migrant newcomers are entitled to receive study guidance in their mother tongue, which comprises support in a learning context (Reath Warren 2017). Swedish as a second language (L2) is offered when Swedish is not a pupil's mother tongue. The corresponding course for adults is Swedish for immigrants (SFI), which has four proficiency levels.

Ganuza and Hedman (2015) have identified a number of problems associated with the non-mandatory status of the school language courses, the status of mother tongue teachers and the insufficient time given to the subject. However, research shows that, in spite of the perceived difficulties, pupils who attend these lessons often benefit from their studies (Bylund and Díaz 2012). Indeed, the benefits of mother tongue instruction have been observed in Somali children regarding their reading comprehension skills in L2 Swedish (Ganuza and Hedman 2019). Similarly, Reath Reath Warren (2017) stated that study guidance in the mother tongue in both Sweden and Australia enhances the learning of newly arrived pupils. Finally, in a study of bilingual speakers of Spanish and English in the USA, MacSwan et al. (2017) found that mother tongue proficiency led to general cognitive improvements in the bilingual speakers' academic studies.

In the Swedish context, there are sociological studies carried out on migrants' narratives on their experiences, such as Adedeji (2021) on Somali migrants, Dahlstedt and Fejes (2019) on career choices among young migrants and Ood et al. (2016) who conducted a study on ageing migrants from the Western Balkans. Additionally, narratives are often used when investigating identities and experiences of multilingualism (Pavlenko 2006; Thompson 2020) and also to describe the linguistic trajectories, like in the study on linguistic trajectories conducted by Soler and Roberts (2019) showing how ideologies grow and are shaped by complex interaction in two multilingual couples living in Sweden. A final example is Hedman and Magnusson (2021), who conducted research on the construction of transnational identities in a student's narrative in mother tongue instruction. Still, SpanishSwedish bilingual migrants' own narratives on their linguistic trajectories, viewed from different decades, have not yet been analysed. By applying a temporal perspective in the selection of participants, comparisons over time will be possible to make.

The current study is based on the above-described Swedish context and aims to investigate how members of the Chilean community express not only their L2 trajectories (The Douglas Fir Group 2016) but also all their multilingual repertoires using semiotic resources) describing how they became a part of Swedish society and the attitudes behind their multilingualism over time. The concept of linguistic trajectories used in this study includes all their multilingual linguistic repertoire (The Douglas Fir Group 2016).

In order to study how individual language identities are built and are related to societal events and understanding of language policies, in the following paragraphs, the micro, meso and macro levels (The Douglas Fir Group 2016) will be presented in which the analysis of language identity is organised and structured.

\subsection{Micro, Meso and Macro Levels. Ideology and Processes of De/Legitimisation}

When analysing multilingualism, The Douglas Fir Group (2016, p. 24) differentiates between micro, meso and macro levels. Learning languages other than the mother tongue is considered to be "an ongoing process that begins at the micro level of social activity". Furthermore, according to Rymes (2010), during this communicative process, the speaker develops a multilingual repertoire when engaging with others in specific multilingual contexts of action and interaction. Situations involving linguistic contact require the 
use of every available multimodal resource (The Douglas Fir Group 2016). Or, quoting Canagarajah (2007, p. 929), the speaker shuttles between communities. At the micro level, the speakers engage in different social activities in interaction with people from different cultures. This social contact contributes to their acquisition of multilingual repertoires, which will increase according to their interaction capability, their open-mindedness towards other cultures and their increasingly growing inclusive ideologies. Meaning-making is a sociocultural activity that takes place with others using different semiotic resources and multimodal mechanisms, which collectively stimulate their capacity to combine all their semiotic resources in order to create meaning, or agency (Bezemer and Kress 2016).

Social contact at the micro level engenders communicative contexts at the meso level. These are shaped by particular sociocultural institutions and sociocultural communities such as family, school, neighbourhood, workplace, places of worship, social organisations such as clubs, community sports and political parties, as well as various kinds of online forums (The Douglas Fir Group 2016, p. 24). These institutions and communities affect access to specific types of social experiences and the creation of a social identity.

Finally, at the macro level, sociocultural institutions and communities develop ideological structures orientated towards language use and language learning based on cultural, political, religious and economic values and ideologies. The individual participates and contributes at the macro level, acting in locally situated contexts of action and interaction.

Macro level ideologies/legislation are integrated into our study. The implicit ideologies of Swedish linguistic and social policies, as well as social actors, processes, events or circumstances relating to migration, are legitimised or delegitimised by the speakers according to their respective experiences. According to Fairclough, the concept of ideology is defined and used as "representations which contribute to reproducing and transforming social relations of power and domination" (Fairclough 2010, p. 46). Wodak et al. (2009) and Benke and Wodak (2003) consider the strategies of legitimisation or delegitimisation that shape the macro strategies for the perpetuation or transformation of the status quo. Finally, strategy is defined in De Cillia et al. (2015): “The concept of strategy generally denotes a more or less accurate plan adopted to achieve a certain political, psychological or other kind of objective" (De Cillia et al. 2015, p. 44).

Crucial to the understanding of identity making, the construction of ideologies and the use of strategies is the concept of space, since it is linked to communities, practices and cultures (Canagarajah 2018). The experience of and individual positioning within linguistic and sociocultural communities engender different degrees of a sense of embeddedness and anchoring. Consequently, these concepts, together with theories of indexicality, are presented in the following section.

\subsection{Space, Transnational Interconnectedness, Sense of Belonging, Embeddedness, Anchoring, Indexicality, Signs of Inclusion vs. Exclusion}

According to Canagarajah (2018), the migrant's linguistic trajectory connects different transnational usages. These usages are intertwined and interrelated. Consequently, to fully understand an individual's linguistic background, it is important to understand language as comprising dynamic and complex systems, socially constructed, which are situated in time and space, and not as isolated systems.

The concepts of space and place are frequently used to construct language identity discourse and shape social life. As Canagarajah (2018) puts it, these concepts are not delimited by physical places or temporality but are context-dependent, active and agentive parts of discourse. Space is a holistic and contextually bound concept that refers to history, geography and society as it emerges in discourse. It is a condition for social practices: "While spatiality shapes social life, people shape the material environment" (Canagarajah 2018, p. 33). According to the same researcher, place equates to the formation of these meanings and shaping human perceptions. Another concept that is organised in relation to space is social embeddedness (Beswick 2020), understood as the positioning inside or outside events and communities. It is used in this study to explore the multilingual repertoires and expressions of belonging. The concept of anchoring is associated with 
references to the different traditions, habits or activities that are situated in different spaces, which means that new social environments are created when crossing social boundaries. As a consequence, heterogeneous language is used at the intersection of different cultures.

It is possible to link the concept of transnational interconnectedness to L1 versus LX Dichotomy: The Language-Usage-Identity State Model (Thomas and Osment 2019), a model in which language identities are described in terms of degrees of usage and the different levels of identification are described as the introjection of identity in varying degrees. Moreover, Thomas and Osment (2019) conclude that interconnectedness is the relationship between different cultural communities, defined by language usage. These communities are described in the discourse and could also be seen as being spatially and temporally situated. In other words, the model operationalises the theories of inclusion-exclusion as introjected identity, which is compatible with the construct of social embeddedness, previously mentioned in the text.

We also consider two more concepts: home and homeland, as described by both King and Ganuza (2005) and Ganuza and Hedman (2017). The former analyses patterns of national, cultural and linguistic identification among Chilean-Swedish transmigrant adolescents living in Stockholm. They focus on the process of constructing the identity of these adolescents. King and Ganuza (2005, p. 180) define identity as "a person's understanding of who they are $[\ldots .$.$] ". This identity is fluid, contextually embedded and constructed through$ interaction.

For these researchers, home and homeland are key notions associated with identity, which is changing and represents an ambiguous situation for transmigrant adolescents, who feel and identify themselves as being more Chilean in Sweden, whereas they feel more Swedish when they return to Chile when visiting family and friends. In this sense, we agree with Pennycook and Otsuji (2015) and Beswick (2020), who consider that the spatiotemporal context actively participates in communication and in the construction of identities.

Finally, registers, accents and varieties create indexicality, which is the connotation of signs, and multimodality of language (Blommaert and Rampton 2011). How indexicality is used and received in the communication might rely on the status of the speaker.

The Chilean migrants in the current study describe multilingual practices and superdiverse contexts, which will be the focus of the following section.

\subsection{Superdiversity and Translanguaging}

The multilingual repertoire could be described in terms of superdiversity, which is the dynamic construction of identities based on the fact that people from different linguistic backgrounds share and incorporate different perspectives. There is no doubt that learning and multilingual identities are stimulated in social practices and communities in which affinity spaces lead to agency, as described by Bezemer and Kress (2016). Translanguaging, as defined by Spotti and Blommaert (2017) and Vogel and Garcia (2017), is a part of superdiversity and reflects the multilingual repertoires.

Spotti and Blommaert (2017) define this notion as the speaker's complex and active use of a repertoire of linguistics features. They analyse how languages operate among migrants in their social interactions within heterogeneous contexts. Indeed, the multilingual possesses a dynamic linguistic system in which the different resources are used for different purposes (Grosjean 2010; Herdina and Jessner 2002; Thompson 2020).

Finally, this viewpoint harmonises with the multilingual turn. This is a new positioning in which the normative native speaker is replaced by a more situated and authentic multilingual speaker and in which linguistic skills are seen as dynamic and emergent rather than closed, isolated systems (The Douglas Fir Group 2016). This is the point of departure of our investigation, in which communication and social interaction are contextually situated. Among multilingual speakers' affinity groups and affinity spaces promote agency (Bezemer and Kress 2016), learning and the formation of their respective identities. 


\section{Materials and Methods}

\subsection{Method and Design}

In accordance with the objectives of this research, the method of analysis is qualitative (Angouri 2010; Denzin and Lincoln 2012) with an interpretative design based on critical discourse analysis (De Cillia et al. 2015). It covers descriptive and interpretative levels. This flexible design (Mendizábal 2009) was chosen as it favours recursivity between theory and empirical data and allows for reformulation of the research questions and the categories of analysis that emerged from the interviewees' discourses.

Regarding validity, the term is used according to the insight of Mendizábal (2009), who considers that there is not just one criterion for judging qualitative research but various criteria. Firstly, the delimitation of phases-the identification of units of analysis, an explicit statement about the possibility of accessing the research area, a description of data collection techniques, a preliminary outline of the way in which the analysis will be conducted and an explicit statement about potential biases. Secondly, the theoretical framework of this research and finally, purposes of the research that have been adapted to the requirements of social pertinence. Thirdly, it is not the author's intention to generalise the results of this research but to provide a deep understanding of the cases chosen according to their relevance. The triangulation of data and interpretative theories allowed for rigorous quality control.

\subsection{Data Collection and Shaping of the Corpus}

The corpus comprises 10 interviews conducted with 10 Chilean interviewees who moved to Sweden from 1970 onwards. The 10 interviewees shared their narratives about their linguistic trajectories in semi-structured interviews with a Chilean researcher. The interviews were conducted in Spanish. The interviewees were recruited according to the decade they arrived in Sweden. Their ages varied. All of them gave their informed consent (see Appendix A). The interviews were recorded and transcribed verbatim. Table 1 shows the interviewees and the decade of their arrival. In order to ensure the interviewees' anonymity, each participant is represented by a letter, as shown in the table.

Table 1. Decade and number of interviewees.

\begin{tabular}{cc}
\hline & Decade and Number of Interviewees \\
\hline 1 & $1970, \mathrm{~A}$ \\
2 & $1970, \mathrm{~B}$ \\
3 & $1970, \mathrm{C}$ \\
4 & $1970, \mathrm{D}$ \\
5 & $1980, \mathrm{E}$ \\
6 & $1990, \mathrm{~F}$ \\
7 & $1990, \mathrm{G}$ \\
8 & $2000, \mathrm{H}$ \\
9 & $2000, \mathrm{I}$ \\
10 & $2000, \mathrm{~J}$ \\
\hline
\end{tabular}

We experienced some difficulty accessing the potential interviewees. This was finally achieved by using the same procedure that was used for all the other adult interviewees. Academics and ex-academics from different universities acted as links with the potential interviewees. In this way, the snowball technique, which involves requesting the collaboration of each interviewee in order to facilitate contact with other potential interviewees among the people from their circle of acquaintances, was avoided. In addition, a higher level of heterogeneity was attained among the interviewees.

Despite these precautions regarding the selection of the interviewees, the researchers were very aware of the potential bias or partiality in their choice of interviewees. However, identifying another method would have proved difficult, apart from the self-motivation on the part of the interviewees to be interviewed. 
A semi-structured interview was chosen for the following three reasons: Firstly, even when the interview was based on a number of issues or questions, the interviewer did not necessarily confine themselves to such issues or questions. Instead, they were at liberty to introduce further issues or questions in order to communicate more precise concepts or obtain more information about the desired topics. This was essential for meeting the objectives of this research, given the sensitive nature of the topics being discussed. In other words, the order of the questions could be changed or the interviewer could go into more detail, depending on the direction of the interview and the kind of responses given by the respective interviewees.

Secondly, because the interviewees had difficulty referring to certain subjects relating to their migration, on certain occasions a degree of flexibility was required on the part of the interviewer, which would not have been the case had the interviews been structured. Thirdly, it was decided not to choose non-structured or open interviews because, according to the goals of this research, the topic of memory has great potential. Consequently, it would not have been possible to cover all the topics in 45 or $60 \mathrm{~min}$ (approximate duration of each interview).

As asserted by Flick (2004), it is important to verify that knowledge constructed by researchers is based on the construction of meaning of the individual being studied. As a means of validation, pilot questions were asked to a group of people with a similar profile to that of the interviewees in order to determine whether the questions were comprehensible, and whether they would elicit the type of information being sought. By way of validation, the document containing the interview questions was given to two academics with expertise on the topics of the interviews being conducted. The researcher implemented the proposed changes that were considered relevant.

All subjects gave their informed consent for inclusion before they participated in the study. The study was conducted in accordance with the Declaration of Helsinki, and the protocol was approved by the Ethics Committee of Stockholm (2017, vol. 5, p. 3) Swedish Research Council (2011) and the Ethical Scientific and Bioethical Committee (el Comité Etico Científico y Bioético), Pontifical Catholic University of Chile (Pontificia Universidad Católica de Chile), code: BIOEPUC_H170-2018.

\subsection{Data Processing}

\subsubsection{Transcriptions}

The transcription of the interviews was carried out by the same interviewer so that they could become deeply familiarised with the resources used by the interviewees in the discursive construction of their respective linguistic trajectories. The interview transcriptions included verbal elements only.

\subsubsection{Analytical Stages}

In order to meet the objectives of our study, the analysis methodology has been organised into descriptive and interpretative phases of a qualitative nature. The corpus has been analysed from the construction of intersubjective significations. This has allowed an interpretative analysis to be conducted and to place the discourses as part of the social practices that materialised in the discourse practices.

The units of analysis are the clause complex ${ }^{1}$, comprising the interview fragments that included richer data in terms of both detailed information and appraisals. The analysis comprised three phases.

\footnotetext{
1 "The clause complex is formed out of a linear sequence of clause nexuses; each nexus consists of a pair of related clauses [ ... ]. Many clause complexes are linear sequences of this kind. But we also often find internal bracketing, or nesting" (Halliday and Matthiessen 2004, p. 376).
} 


\section{First Phase}

The first phase of analysis was articulated regarding the micro level (The Douglas Fir Group 2016), in which different semiotic resources were used in the actions and interactions carried out during the process of acquiring the new language.

\section{Second Phase}

In the second phase, the meso level (The Douglas Fir Group 2016) was analysed in two aspects. On the one hand, we analysed how different sociocultural institutions and sociocultural communities create conditions that shape diverse social identities. On the other hand, the meso level relates to the diverse senses of belonging and different identity languages. Temporality was used to detect variations in the different narratives regarding identity making and the process of belonging.

Third Phase

In the third phase, the macro level (The Douglas Fir Group 2016) was analysed, which relates to various ideologies (Fairclough 2010) that influence both the meso and the micro level within their locally situated contexts of action and interaction.

Finally, taking into consideration the categories proposed by De Cillia et al. 2015, the various ways were analysed in which the interviewees discursively legitimised or delegitimised social actors, processes, events or circumstances, according to the sense of belonging and the ideology of each interviewee.

\section{Results and Discussion}

Considering the several adaptation processes in the Swedish society, this section examined how the Chilean migrants discursively developed their linguistic trajectories in relation to different topics according to their different experiences.

The causes of transmigration that the Chilean migrants described were generally associated with political motives and described as forced migration, as can be seen in the following example.

Example 1. I came to Sweden in 1977 for political reasons. [ . . . I I hadn't planned to move to Sweden, but my circumstances forced me. When I arrived in Sweden, it was a very emotional experience to enter a foreign country that welcomed me with open arms-and that there were no risks. $(1970, A)$

However, other interviews focused more on family reunification, indirectly derived from the Chilean situation, which led the refugees to seek a better life in a country with a better social security system and more opportunities to study and work, as shown in Example 2.

Example 2. I came to Sweden looking for better opportunities. I had siblings living here. One of them arrived here in the 1970s after the coup. The other two were asylees. In 2001 I requested temporary residence. At the time I was living with a Swedish citizen and because of this, the Swedish state was able to offer me Swedish classes for foreigners. $(2000, \mathrm{H})$

It is noteworthy that, to a greater or lesser extent, when talking about their linguistic trajectories, all the interviewees related their experience to the Chilean dictatorship based on their own experience or their relatives' experience.

The oral or written transmission of the latter to younger members of the family awakened a desire in them to migrate to a country like Sweden, which offered a better standard of living, particularly regarding social security, education and free health care, as opposed to Chile, where privatisation gradually increased the socioeconomic gap among Chileans (Mella 1990, p. 26). 


\subsection{Linguistic Trajectories at the Micro Level}

The initial adaptation process was similar for all interviewees, as can be seen in the following examples.

Example 3. At first it was hard to be here and I experienced a lot of anguish. Cleaning windows in empty offices meant that I didn't have to talk to people because not being able to understand and not being able to communicate was distressing for me. Over time, I gradually learned the language. First, I attended the Swedish classes offered free for foreign adults and I kept improving until I graduated and started working at the university. (1970, A)

Example 4. I suffered a lot from terrible depression, but it helped me. Initially, while my husband was working, in order to learn Swedish, I would go to the community library and ask for children's books in Swedish. I also listened to a daily lottery programme. At first I didn't understand anything but that's how I eventually learned numbers in Swedish. After three months I started working in a bakery, ordering bread. I was trying to do my job as perfectly as possible so that nobody would ask me or tell me anything. At first it was very hard but one day I was given information about a Chilean teacher who gave private Swedish lessons to Latin-American people. She gave me a lot of advice on how to pronounce Swedish vowels. Today, as a Swedish teacher, I use many of these strategies with my own students, who speak different languages such as Arabic, Spanish, Turkish and Finnish. $(1970, B)$

At the micro level, the interviewees described their initial immersion difficulties due to their lack of Swedish. They also highlighted the strategies that helped them improve their linguistic proficiency, which opened up Swedish society to them as they interacted in different multicultural contexts. Actions and interactions in diverse educational and sociocultural institutions (at the meso level) required them to use various semiotic resources at the micro level. In this way, the Chilean interviewees managed to acquire a varied linguistic repertoire.

At a micro level, all the interviewees employed diverse semiotic resources (verbal, prosodic, interactional, gestures) to describe their engagement in multilingual contexts of action and interaction, relating to their country of origin (Chile) or their host country (Sweden).

In her account, one of the interviewees $(2000, \mathrm{H})$ included details of the strategies of teaching Swedish in free courses offered by the Swedish state, as can be seen in Example 5 .

Example 5. Here, I was exposed to Swedish all the time. We were given activities, tasks relating to communication skills that we could put into practice outside of class, such as shopping, visiting an exhibition, going to the theatre. The classes used a communicative approach. The teachers put a range of strategies into practice. There were many audio-lingual activities: listening, repeating, inferring rules, although there was not much teaching based on a purely grammatical approach because all students in the same class had different mother tongues, so it was not worth doing much translation. The teacher believed that explaining a rule of grammar was more complicated than trying to teach it through exposure to dialogue, where you could infer a rule of grammar. $(2000, H)$

This interviewee positively evaluated the communicative approach as a way of teaching Swedish in a multicultural environment, in which the majority of students spoke a different mother tongue. Thus, dialogue and tasks relating to daily life were the most effective strategies for acquiring the new language.

Despite the common elements in all the interviewees (attending the SFI and initial difficulties due to their lack of Swedish), their linguistic trajectories had a facilitating dimension in the case of two interviewees: 1970, B, and 2000, H. The former interviewee had knowledge of English and French grammar, which they had acquired in Chile. The latter interviewee also had knowledge of English. She stated: "English was initially the gateway to communication in Sweden". In contrast, the process of immersion into Swedish 
society by the other interviewees was hampered by them having no second language when they arrived in Sweden.

\subsection{Linguistic Trajectories at the Meso Level}

Despite belonging to different age groups and emigrating in different decades, the young man (1970, A) and the young woman (1980, E) shared similar feelings when they arrived in Sweden: tranquillity in a safe haven (1970, A) and happiness for being welcomed in the neighbourhood and at school (1980, E), as can be seen in Example 3.

Example 6. I had my primary schooling in Chile and then came to Sweden with my twin sister and my mother, who was a political refugee. It was a very difficult situation in Chile and very hard at the time. Travelling here was difficult but I was happy. We were very well received at the school and in the neighbourhood when we arrived. There were other Chilean refugees or refugees from other South American countries who shared the same experience; many children our own age with the same experience. We arrived on a Saturday and on the Monday we went to school. We signed up and started leading a normal life. $(1970, B)$

In this example, the interviewee $(1970, \mathrm{~B})$ contrasted the negative Chilean situation with her feelings when she arrived in Sweden with her family. In Sweden, refugees were welcomed both at school and in their own neighbourhood, which were spaces she also shared with other children from refugee families. This interviewee described the meso level by highlighting Swedish social spaces as being situated and shared contexts between Swedish people and Chilean refugees.

She described the process of learning Swedish with her sister and her mother. The interviewee also stated that courses on maintaining the mother tongue were included in the curriculum. These kinds of courses are called MIT (Mother Tongue Instruction). Her linguistic trajectory was also enriched by attending summer camp, as shown in the following example.

Example 7. The first two summers in Sweden we were sent to a summer camp in Northern Sweden, living with other Swedish families who also needed social support. So we became friends. We have remained friends with some of them to this day. Attending summer camps was very common. Historically, it started with this opportunity being offered to children who had less resources and who lived in cities with no access to nature. The summer camps made it possible to learn Swedish and Swedish customs, how to eat, how to do things; you learned that there were other ways of living that were equally valid. For me, it was a very positive experience. For example, I know the names of flora in Swedish, but hardly any of the names in Spanish. In Sweden it is very important to know the names of flowers that are planted in the summer or autumn. (1970, B)

The time spent in the summer camp gave this interviewee access to Swedish nature. Social activities and interactions at the micro level also offered the interviewee the opportunity to improve her proficiency in Swedish and learn more about Swedish customs.

At a meso level, summer camps were other situated contexts in which the interviewee was able to interact with other migrants and Swedish people. These kind of communities at the meso level are strongly characterised by pervasive social conditions that affect the opportunity and nature of people attempting to create social identities in terms of agency (Bezemer and Kress 2016).

Additionally, at a meso level, another common element highlighted by all the interviewees was the opportunity to study Swedish in free courses offered by the Swedish state: SFI (Swedish for immigrants). These courses provide language skills for future study or work. One of the interviewees described the organisation of Swedish teaching in those days and also her own linguistic trajectory, as shown in the following example. 
Example 8. The organisation of courses has changed a lot over time. When I arrived in Sweden you had to do a kind of diagnostic test with a native teacher who would interview you and, according to the results of the test, you were assigned a number of hours. Since I knew nothing, the teacher told me I would have to study for around $350 \mathrm{~h}$ allotted over many months. However, I knew that it would be impossible to learn a language spread over $350 \mathrm{~h}$ twice a week. I thought: "It's going to take me forever to finish." For this reason, because my school taught from 08.00 in the morning until 19.00 in the evening, I attended classes from when the school opened until it closed because no one stopped me from doing this. This meant I attended every class. It went on like this for three months. $(2000, H)$

According to Steinmayr et al. (2019), motivation is a fundamental factor in the acquisition of a new language, as it is demonstrated by the interviewee through her discourse, in which she emphasised the importance of her total dedication to studying Swedish in order to achieve her final goal: the recognition of the degree she had obtained in Chile, as she explained in another part of the interview.

Additionally, depending on their sense of belonging to different groups, the interviewees constructed their identity. Their use of languages involved interacting with identitymaking as they attempted to create interconnectedness (Thomas and Osment 2019).

All interviewees recognised the importance of crossing borders (Watt and Llamas 2014) from the monolingual Chilean society to the corresponding multilingual Swedish environment. This new environment comprising other cultures and heterogeneous languages created new opportunities for them and their families.

In Beswick's terms (2020), all interviewees in our study achieved social embeddedness and anchoring. They reached their respective individual positions in a Swedish multicultural context. At the same time, they achieved anchoring, which implies being rooted in social phenomena such as habits and traditions and contributes to the crossing of symbolic boundaries and processes of inclusion in Swedish society. According to their respective accounts, they acquired strategies over time for better social incorporation and interacting with other cultures and different languages. This openness allowed them to enhance their linguistic repertoire, as well as improve their incorporation into Swedish multilingual society.

In addition, throughout the interviews, both interviewees stressed the importance of translanguaging (Spotti and Blommaert 2017), even though neither of them actually used this specific term. The perspective of the interviewees illustrates and harmonises with the goals given by the so-called multilingual turn due to their learning Swedish and, also, unexpectedly, expressions in other languages such as Finnish, Persian and Arabic, among others.

Thus, in these new ways, identities were negotiated within different social realities. In the discourse of our interviewees, we did not note any fluctuation in the construction of identities based on the weakening or strengthening of certain ties according to the experiences of each one of the interviewees in their contact with different communities and places, as shown in the following example.

Example 9. At first it was hard to be here. I experienced a lot of anguish. However, when I returned to Chile after many years, I felt like a foreigner. I'm from neither here nor there. I'm from nowhere. At that time, Swedish people were very open to migrants. I attended a Swedish course for migrants with 10 or 15 people of different countries: Romania, Finland, Middle Eastern countries and other languages that I didn't understand. Some of the teachers were really good but there were also volunteers without sufficient preparation. Now, everything is much more organised. Now, according to my nephew, everything is much more organised. (1970, A)

Both spaces influence the fluctuating identification of the interviewee with the values of both countries. Intellectually, he identified himself more with Chile, but Sweden was the country in which he received his highest of academic training and where his children 
were born. At the same time, this interviewee delegitimised volunteer teachers who had received no formal training.

According to Blommaert and Rampton (2011), most interviewees verbally construct their language identity in their discourse, making constant references to their two countries of belonging with spatial indexical expressions such as "here", "there" and temporal expressions such as "now", "before" or "at that time", as can be seen in the following example.

Example 10. At that time, schools were run by the State. Now they are run by local municipalities. We were all subjected to a period of school placement for children who did not have Swedish as their first language. They are still called Newcomer Programmes. There were special classes, special groups for children who didn't understand Swedish or who were learning Swedish. These children always belonged to classes that offered subjects such as gymnastics, visual/plastic arts, etc. (1970, B)

In this way, the interviewees showed an identity that was in a constant process of construction, vacillating between Chile and Sweden as their countries of belonging. Indexicality (Blommaert and Rampton 2011) explains how processes of inclusion and exclusion and identities are built, as shown in Example 11.

Example 11. The school I'd attended in Chile was much more advanced. In Sweden, the Spanish teacher would update us with the Swedish curriculum, but I already knew it. What I learned most at Swedish elementary school was Swedish and English, as well as religion. At my Chilean school, religion was optional and my mother had decided that we did not need to attend religion lessons. So I had no idea about anything. At the time, religion was totally new to me. I learned about Christianity, Hinduism, Islam and so on. (1970, C)

The interviewee advanced at the macro level because, in this identity process, she acquired new ideologies by adopting her own positions on different world religions, elements that had been unknown to her when she lived in Chile. According to De Fina (2013), accented varieties and diversity of knowledge are indexes of identity in everyday communication.

\subsection{Linguistic Trajectories at the Macro Level}

At the macro level, all interviewees described their ideology (Fairclough 2010) linked to their changes in mentality, clearly connecting with their immersion in Swedish society. They emphasised the importance of sharing with other diverse cultures. These exchanges are considered to be a valuable form of enrichment, as can be observed in the following example.

Example 12. Working with people who don't speak your language is also enriching for a number of cultural reasons. Being in contact with people who are from so many different places is wonderful because it allows you to gain knowledge of things you didn't know about before, such as how people live in Africa, what they eat, what their languages are like. You also learn that not all people who speak the same language share the same traditions, as well as how they changed their ways of viewing the world when they arrived in Sweden. $(2000, H)$

All the interviewees emphasised that contact with a multicultural society was the greatest benefit of living in Sweden. This contact with multiple languages and way of life allowed the interviewees to open their minds and become more tolerant towards issues that not only related to migration but also to sexual orientation, for example. These new ideological perspectives of the interviewees shaped their sense of belonging to different groups, as well as their identity and their agency within situated contexts of action and interaction.

The interviewees discussed their trajectories, which are their descriptions of the experience of being Swedish speakers and how they perceived their different repertoires (Vogel and Garcia 2017) in Swedish and in Spanish. This was observed if and when it 
emerged in their discourse (semi-structured interviews). No questions were specifically asked with the intention of triggering a response.

A Chilean interviewee who teaches Swedish and Spanish at primary school was concerned. This Chilean-Swedish woman explicitly demonstrated her awareness of her linguistic repertoires of both languages using examples of daily life, as well as in different academic fields, as shown in Example 13.

Example 13. Over time I discovered that many Swedish words are derived from Latin or English. For example: escuela (Spanish) school (English) schola (Latin) skola (Swedish). I use Swedish every day, at work, shopping, for everything. At home we speak 80\% Spanish and 20\% Swedish. My children speak Spanish fluently but although I speak to them in Spanish, they respond in Swedish. $(1990, F)$

This interviewee discussed her trajectories, which are her description of the experience of being a Swedish speaker and how she perceived her linguistic repertoires in Swedish and in Spanish. This Chilean-Swedish woman highlighted the importance of combining both languages by explicitly using examples of daily life, as well as from different academic fields, which we consider to be an example of the fact that the multilingual's linguistic system is a complete one in which the different languages are used for different purposes. Example 13 shows the interconnectivity between the linguistic systems, see further Spotti and Blommaert (2017) and also Grosjean (2010), Herdina and Jessner (2002) and Thompson (2020).

Using both languages responded to her individual choices depending on her participation in diverse intergroup encounters, including her own family (Saguy and Kteily 2014). However, the interviewee emphasised the different reactions of her children, who speak both Spanish and Swedish, but prefer to respond in Spanish.

In summary, our interviewees recognised the impact of the growing role of superdiversity (Vogel and Garcia 2017) in all aspects of their social life because it promoted the dynamic construction of identities through the incorporation of different perspectives. Consequently, this was reflected in their discursive and semiotic practices because of their appropriation of cultural resources that form part of diverse communities and places. All of them experienced space as a concept that refers to history and geography and that emerged in their discourse in relation to Chile or Sweden. According to Canagarajah (2018), our interviewees conceived spatiality that was shaped by various social meanings relating to Chile or Sweden.

In the fluctuating construction of their identity, the interviewees vacillated in their conception of home and homeland, as can be seen in the following example.

Example 14. I think that one of the best things about Sweden are the greater opportunities for women. I think this is quite commendable because in Sweden, women can earn the same as men for doing the same type of work. You feel a great sense of security as a woman and you are not harassed in the street. Compliments associated to a woman's body are very frowned upon. Even on television, advertisements in which a woman's body is associated with a product that has nothing to do with her gender are prohibited. I think that's really good. My greatest difficulty is not about my interaction with Swedish society; it is more to do with my relationship with my family, who live far away; this still makes me sad. The journey to Chile is long and expensive. I have a nostalgic love for Chile, despite its economic inequalities. These economic inequalities are the most unattractive aspect of Chile. However, at the same time, there is greater social interaction in Chile. People are committed to mobilising themselves: going out on the streets, sharing food. $(2000, H)$

In this way, she showed an identity that was in a constant process of construction, vacillating between Chile and Sweden as her countries of belonging. She regarded Chile as being home (Ganuza and Hedman 2017) and its remoteness made her homesick. The spatiotemporal Chilean context actively participates in communication and in the construction of identities in terms of Canagarajah (2013) and Pennycook and Otsuji (2015). 
Most of the interviewees experienced and described a sense of belonging to two cultural worlds, not only regarding their own lives but also in relation to the recent migration to Sweden as a consequence of the war in the Middle East, as shown in the following example.

Example 15. Regarding the reception of migrants, the situation has changed. Sweden was one of the European countries that really opened its doors, welcoming large numbers of immigrants as a result of the recent war in Syria. There is a spirit of welcoming but there is also a different spirit that is no longer open to foreigners in the same way. At the present time, being a migrant in Sweden can be a problem. There are certain highly xenophobic people in Sweden that perceive migrants as being a setback because they place a great financial burden on society. However, at the same time, their arrival is a positive thing because many jobs have been created that also serve these groups of migrants. For example, teachers of Swedish as a second language do very well in Sweden because there are many students who need to learn Swedish. There are many social programmes that welcome these migrants. These programmes include social workers, health personnel and personnel working on legal issues. When these migrants start working themselves, they pay income tax. So, the state invests in them but then they give something back to society; then it's a win-win situation. $(2000, H)$

In this way, the interviewee described her own ideology (Fairclough 2010) on the subject. She looked positively at the recent arrival of migrants as an opportunity to create new jobs for both the newcomers and other members of Swedish society who collaborate in the immersion process of foreigners.

Other benefits of the current inclusion of migrants include the presence of certified teachers and interpreters in different educational institutions, as seen in the following example.

Example 16. At first it was very difficult because I only knew a little English and no Swedish. It was difficult to find an interpreter. These days, you can book an interpreter in any language (Punjabi, German, Arabic, Turkish, Spanish, etc.), in person or by phone. The cost will be covered by the specific location: court, hospital, doctor's office, interview, school, parents' meeting, for example. $(1990, F)$

This interviewee described her ideology regarding the important role of interpreters in Swedish society. In another part of her interview, she emphasised the need for teachers to be certified.

All interviewees agreed that Sweden's welcoming spirit was not compatible with the emerging perspective of the ultra-right, which was unanimously delegitimised by all our interviewees. At the macro level, their ideology was in accordance with the welcome they received when they first arrived in Sweden.

The most salient differences observed between the decades concern the experiences expressed on the micro and meso levels regarding the organization of the classes of SFI. In the beginning, there was no preparation for the high numbers of refugees in need for classes in Swedish. The teachers or volunteers were not sufficiently prepared. According to the interviewees who arrived in the 1970s, their younger family members have experienced a better provision of teaching. Likewise, the teaching is viewed differently, as better organized and situated, by the migrants who arrived later.

Another important point of comparison between the decades is the relation to the Spanish-speaking community which, by the time of 1990, was an established one. This fact is present in the later arrived migrants' narratives when they refer to the Spanish-speaking community, the Chilean teacher and so on.

Dahlstedt and Fejes (2019) point out that belonging or not belonging to the Swedish community is important to the young migrants of their study and the feeling to "be out of place" (2019, p. 76) is mentioned. Belonging and embeddedness not only to the Swedish society but to the Spanish-speaking community in Sweden is mentioned in the present 
study. In all the narratives, the usage of languages and the reference to space still seem to be central to their feeling of belonging.

Interestingly, the usage of languages and the reference to space still seems to be central to the interviewees. At a meso level, several participants express interconnectivity and superdiversity describing their language use. The later-arrived migrants are more explicit at this point, perhaps because of prior knowledge of other languages or, possibly, due to societal changes. It is also interesting to see how, at a macro level, the later-arrived migrants express their ideology when referring to societal changes in Sweden.

\section{Conclusions}

The analytical stages described in the Methodology section gave us access to the ways in which Chilean migrants who arrived in Sweden in different decades since the 1970s discursively developed their respective linguistic trajectories according to their experiences, sense of belonging and their feelings about Swedish migrant policies.

At a micro level, all interviewees employed diverse semiotic resources (verbal, prosodic, interactional, gestures) to describe their engagement in multilingual contexts of action and interaction, relating to their country of origin (Chile) or their host country (Sweden). The transmigration was generally linked to political motives and described as forced migration. However, in other cases, it was more about family reunification, indirectly derived from the Chilean situation, which led them to seek a better life in a country with a better social security system and more opportunities to study and work.

Moreover, at the micro level, the interviewees emphasised their initial immersion difficulties due to their lack of Swedish. However, they also highlighted the strategies used for language learning in multilingual and multicultural contexts, which enriched their immersion in Swedish society.

At the meso level, interaction with different groups and communities (school, university, SIF and MTI, for example) allowed the migrants to improve their linguistic repertoire and therefore their access to university studies and better jobs. Their sense of belonging to diverse groups allowed them to build an identity that fluctuated between Chile and Sweden and use different languages (Spanish, Swedish, English), including their different repertoires.

At the macro level, the interviewees discursively developed their own ideological perspectives regarding the lifestyle of society and the political and cultural expressions of both Chile and Sweden. The migrants' linguistic trajectories connected diverse transnational/translocal usages. They recognised the importance of crossing borders towards a more multilingual context. Our interviewees recognised the impact of the growing role of superdiversity in all aspects of their social life. All the interviewees stated that sharing with other cultures contributed to the process of inclusion. Indeed, both social embeddedness and anchoring appeared in their discourse together with references to diverse language use, which is interpreted as translanguaging. Overall, language use constituted part of their identity-making and process of belonging (Thomas and Osment 2019). The interviewees showed an identity that was in a constant process of construction, vacillating between Chile and Sweden as their countries of belonging. In the fluctuating construction of their identity, the interviewees vacillated in their conception of home and homeland. Indexicality described how processes of inclusion and exclusion and identities are built.

The interviewees shared their own linguistic trajectories regarding the different policies relating to access, acquisition of a second language (Swedish) and maintenance of the first language (Spanish). Expert instruction in L2, the communicative setting of the multicultural language classroom and the linguistic mediators were legitimised, while the process of adaptation and volunteers without sufficient preparation, as well as the new perspective against migrants, were delegitimised. Societal changes were identified as macro strategies that led to the transformation or perpetuation of what was being legitimised or delegitimised. 
Author Contributions: The interviews were conducted by P.B.-D. However, the writing of this article was shared with R.Ö., who collaborated in the effort to identify potential interviewees. All authors have read and agreed to the published version of the manuscript.

Funding: This research was funded by FONDEYCT Project 11181159, sponsored by ANID (Agencia Nacional de Investigación y Desarrollo, National Research and Development Agency) and by the leading research field of Romance Linguistics at the Department of Romance Studies and Classics at Stockholm University, Sweden.

Institutional Review Board Statement: The study was conducted in accordance with the Declaration of Helsinki, and the protocol was approved by the Ethics Committee of Stockholm (2017/5:3) Swedish Research Council (2011) and the Ethical Scientific and Bioethical Committee (el Comité Ético Científico y Bioético), Pontifical Catholic University of Chile (Pontificia Universidad Católica de Chile), Code: BIOEPUC_H170-2018.

Informed Consent Statement: Informed consent was obtained from all subjects involved in the study (see Appendix A).

Data Availability Statement: The data are not publicly available due to restrictions. Data available on request to the corresponding author.

Acknowledgments: The authors of this article would like to express their thanks to the Pontifical Catholic University of Chile (Pontificia Universidad Católica de Chile), the ANID (Agencia Nacional de Investigación y Desarrollo, National Research and Development Agency) and to Stockholm University, particularly the Romance Linguistics sponsorship at the Department of Romance Studies and Classics.

Conflicts of Interest: The authors declare no conflict of interest. The funding sponsors had no role in the design of the study, in the collection, analyses or interpretation of the data, in the writing of the manuscript or in the decision to publish the results.

\section{Appendix A}

\section{Adults Informed Consent Form}

The interviewer who submitted this document has formally asked me to participate in an interview in order to carry out a study being conducted at the Pontifical Catholic University of Chile and Stockholm University. The title of the study is: Chilean Migrants in the Swedish Context from the 1970s Until Recently: The Discursive. Construction of Their Own Linguistic Trajectories.

This study aims to compare the discursive construction of Chilean migrants who arrived in Sweden from 1970 until recently regarding their own linguistic trajectories.

The interviewer informed me that the talk will last 45 to $60 \mathrm{~min}$ and that my participation is voluntary and unpaid. The interviewer also stated that I have the right to refuse to answer any question. I can also terminate my participation at any time if I wish.

If I give my consent the interview will be recorded and the data collected will be used in the study.

The interviewer has also notified me that whatever I say in the interview may be published in academic articles or be presented in conferences, seminars or lectures regarding the study results. I was also informed that the data collected from this interview will be permanently accessible to other researchers and could be used in future studies. If I give my consent, my full name will appear in these publications.

Finally, I have also been informed that in case of requiring further information or any clarification, I can contact the following: 


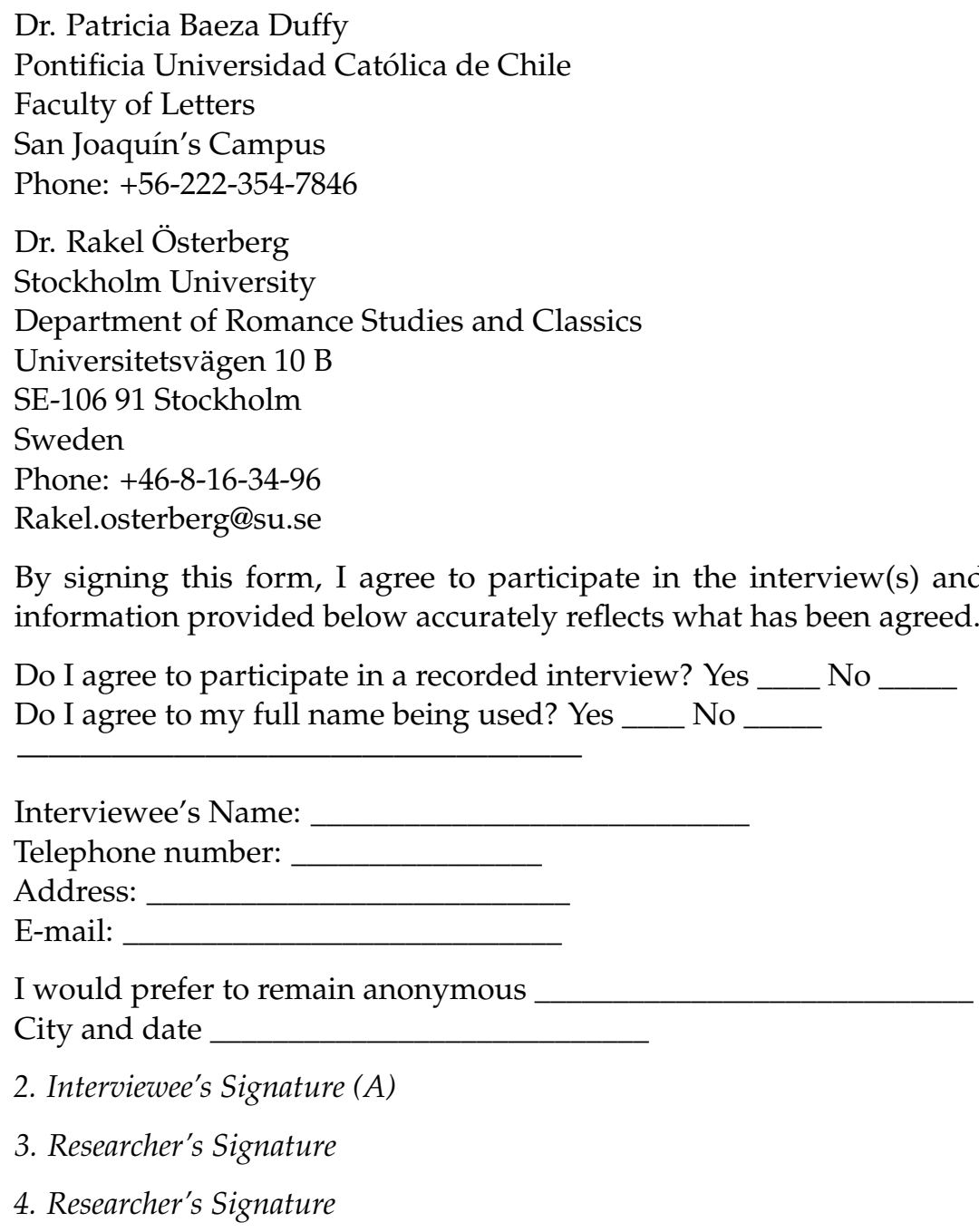

\section{References}

Adedeji, Adekunle. 2021. Social Capital and Migrants' Quality of Life: A Systematic Narrative Review. Journal of International Migration and Integration 22: 87. [CrossRef]

Aktürk-Drake, Memet. 2018. Hur bra har den svenska integrationskontexten varit på att främja balanserad tvåspråkighet? Nordand Nordisk Tidsskrift for Andrespråksforskning, 107-30. [CrossRef]

Angouri, Jo. 2010. Quantitative, qualitative or both? Combining methods in linguistic research. In Contemplating Interviews and Focus Groups. Edited by Lia Litosseliti. Londres: Continuum, pp. 29-48.

Benke, Gertraude, and Ruth Wodak. 2003. The Discursive Construction of Individual Memories. How Austrian 'Wehrmacht' soldiers remember WWII. In Re/Reading the Past. Critical and Functional Perspectives on Time and Value. Edited by James Martin and Ruth Wodak. Amsterdam: Benjamins, pp. 115-38. [CrossRef]

Beswick, Jaine. 2020. Identity, Language and Belonging on Jersey: Migration and the Channel Islands. London: Palgrave Macmillan.

Bezemer, Jeff, and Gunther Kress. 2016. Multimodality Learning and Communication. A Social Semiotic Frame. London: Routledge. [CrossRef]

Blommaert, Jan, and Ben Rampton. 2011. Language and Superdiversity. Diversities 13: 1-21. Available online: www.unesco.org/shs/ diversities/vol13/issue2/art1 (accessed on 18 January 2021).

Bylund, Emanuel, and Manuel Díaz. 2012. The effects of heritage language instruction on first language proficiency: A psycholinguistic perspective. International Journal of Bilingual Education and Bilingualism 15: 1-17. [CrossRef]

Canagarajah, Suresh. 2007. Lingua Franca English, Multilingual Communities, and Language Acquisition. The Modern Language Journal 91: 923-39. [CrossRef]

Canagarajah, Suresh. 2013. Translingual Practice: Global Englishes and Cosmopolitan Relations. London: Routledge.

Canagarajah, Suresh. 2018. Translingual Practice as Spatial Repertories: Expanding the Paradigm beyond Structuralist Orientations. Applied Linguistics 39: 31-54. [CrossRef]

Dahlstedt, Magnus, and Andreas Fejes. 2019. Futures in line? Occupational choice among migrant adult students in Sweden. International Journal of Lifelong Education 38: 787. [CrossRef] 
Dahlström, Carl. 2004. Nästan Välkomna. Invandrarpolitikens Retorik Och Praktik (Almost Welcome. Rhetoric and Practice in Immigrant Policy). Ph.D. dissertation, Göteborg Studies in Politics 87, Göteborgs Universitet, Göteborg, Sweden.

De Cillia, Rudolf, Martin Reisgl, and Ruth Wodak. 2015. La construcción discursiva de identidades nacionales. Andamios. Revista de Investigación Social 12: 153-91.

De Fina, Anna. 2013. Top-Down and Bottom-Up Strategies of Identity Construction in Ethnic Media. Applied Linguistics 34: 554-73. [CrossRef]

Denzin, Norman, and Yvonna Lincoln. 2012. Manual de Investigación Cualitativa. Barcelona: Gedisa.

Donoso, Alejandra, Rakel Österberg, and Enrique Sologuren. Forthcoming. Biliteracidad avanzada en la escritura académica de usuarios bilingües de sueco y de español como lengua de herencia. In Multilingual Insights into a Complex Field of Study: Towards an Equal Academic Exchange. Edited by Natalia Ávila Reyes. The WAC Clearinghouse.

Emilsson, Henrik. 2015. A national turn of local integration policy: Multi-level governance dynamics in Denmark and Sweden. CMS 3: 7. [CrossRef]

Fairclough, Norman. 2010. Critical Discourse Analysis: The Critical Study of Language. London and New York: Routledge.

Flick, Uwe. 2004. Introduction a la Investigación Cualitativa. Madrid: Morata.

Ganuza, Natalia, and Christina Hedman. 2015. Struggles for legitimacy in mother tongue instruction in Sweden. Language E Education: An International Journal 29: 125-39. [CrossRef]

Ganuza, Natalia, and Christina Hedman. 2017. Ideology vs. Practice: Is there a space for translanguaging in mother tongue instruction? In New Perspectives on Translanguaging and Education. Edited by Bethanne Paulsrud, Jenny Rosén, Bóglarka Straszer and Åsa Wedin. Clevedon: Multilingual Matters, pp. 208-26.

Ganuza, Natalia, and Christina Hedman. 2019. The impact of mother tongue instruction on the development of biliteracy: Evidence from Somali-Swedish bilinguals. Applied Linguistics 40: 108-31. [CrossRef]

Grosjean, François. 2010. Bilingual: Life and Reality. Cambridge: Harvard University Press.

Halliday, Michael, and Christian Matthiessen. 2004. An Introduction to Functional Grammar. London: Edward Arnold.

Hedman, Christina, and Ulrika Magnusson. 2021. Constructing success and hope among migrant students and families: A mother tongue teacher's didactic narratives. Language and Communication 77: 93-105. [CrossRef]

Herdina, Philip, and Ulrike Jessner. 2002. A Dynamic Model of Multilingualism: Changing the Psycholinguistic Perspective. Clevedon: Multilingual Matters.

Hyltenstam, Kenneth, and Rakel Österberg. 2010. Foreign language provision at secondary level in Sweden. Sociolinguistica 24: 85-100. [CrossRef]

Hyltenstam, Kenneth, and Tommasso Milani. 2012. Flerspråkighetens sociopolitiska och sociokulturella ramar. In Flerspråkighet. Edited by Kenneth Hyltenstam, Monica Axelsson and Inger Lindberg. Stockholm: Vetenskapsrådet, pp. 17-152. Available online: urn:nbn:se:su:diva-88474 (accessed on 18 January 2021).

King, Kendall, and Natalia Ganuza. 2005. Language, Identity, Education, and Transmigration: Chilean Adolescents in Sweden. Journal of Language, Identity, and Education 4: 179-99. [CrossRef]

Krzyzanowski, Michal, Anna Triandafyllidou, and Ruth Wodak. 2018. The Mediatization and the Politicization of the "Refugee Crisis" in Europe. Journal of Immigrant E Refugee Studies 16: 1-14.

MacSwan, Jeff, Marilyn Thompson, Kerrie Rolstad, Kara McAlister, and Gerda Lobo. 2017. Three Theories of the Effects of Language Education Programs: An Empirical Evaluation of Bilingual and English-Only Policies. Annual Review of Applied Linguistics 37: 218-40. [CrossRef]

Martínez Lirola, María. 2017. Linguistic and visual strategies for portraying immigrants as people deprived of human rights. Social Semiotics 27: 21-38. [CrossRef]

Mella, Orlando. 1990. Chilenska Flyktingar i Sverige. Stockholm: CEIFO.

Mendizábal, Nora. 2009. Los componentes del diseño flexible en la investigación cualitativa. In Estrategias de Investigación Cualitativa. Coordinated by Irene Vasilachis. Buenos Aires: Gedisa, pp. 65-105.

Ood, Qarin, Greta Häggblom-Kronlöf, and Lisen Dellenborg. 2016. Embraced by the past, hopeful for the future: Meaning of health to ageing persons who have migrated from the Western Balkan region to Sweden. Ageing \& Society 36: 649-65. [CrossRef]

Parada, MaryAnn. 2018. Chilean Spanish Speakers in Sweden. In California State University Bakersfield Handbook of Spanish as a Minority/Heritage Language. Edited by Kim Potowski. New York: Routledge, pp. 517-36. [CrossRef]

Parkvall, Mikael. 2015. Sveriges Språk i Siffror: Vilka Språk Talas Och av Hur Många? Stockholm: Språkrådet.

Pavlenko, Aneta. 2006. Bilingual selves. In Bilingual Minds: Emotional Experience, Expression and Representation. Edited by Aneta Pavlenko. Clevedon: Multilingual Matters, pp. 1-33.

Pennycook, Alastair, and Emi Otsuji. 2015. Metrolingualism: Language in the City. London: Routledge.

Philipson, Robert. 2009. The tension between linguistic diversity and dominant English. In Social Justice through Multilingual Education. Edited by Tove Skutnabb-Kangas, Phillipson Robert, Ajit K. Mohanty and Minati Panda. Bristol: Multilingual Matters, pp. 85-102.

Reath Warren, Anne. 2017. Developing Multilingual Literacies in Sweden and Australia: Opportunities and Challenges in Mother Tongue Instruction and Multilingual Study Guidance in Sweden and Community Language Education in Australia. Ph.D. dissertation, Stockholm University, Stockholm, Sweden. Available online: http:/ / urn.kb.se/resolve?urn=urn:nbn:se:su:diva-1447 45 (accessed on 18 January 2021). 
Rymes, Betsy. 2010. Classroom discourse analysis: A focus on communicative repertoires. In Sociolinguistics and Language Education. Edited by Nancy Hornberger and Sandra McKay. Clevedon: Multilingual Matters, pp. 528-48.

Saguy, Tamar, and Nour Kteily. 2014. Power, negotiations, and the anticipation of intergroup encounters. In the European Review of Social Psychology 25: 107-41. [CrossRef]

Salas, Natalia, Felipe Kong, and Renato Gazmuri. 2017. La Investigación Socio Territorial: Una Propuesta para Comprender los Procesos de Inclusión de los Migrantes en las Escuelas. Revista Latinoamericana de Educación Inclusiva 11: 73-91. [CrossRef]

Salö, Linus, and David Karlander. 2018. Semilingualism: The life and afterlife of a sociolinguistic idea. Urban Language and Literacies, 2-14. [CrossRef]

Salö, Linus, Natalia Ganuza, Christina Hedman, and Martha Karrebæk. 2018. Mother tongue instruction in Sweden and Denmark Language policy, cross-field effects, and linguistic exchange rates. Language Policy 17: 591-610. [CrossRef]

Soler, Josep, and Tim Roberts. 2019. Parents' and grandparents' views on home language regimes: Language ideologies and trajectories of two multilingual families in Sweden. Critical Inquiry in Language Studies 16: 249-70. [CrossRef]

SOU. 1983. Olika ursprung-Gemenskap i Sverige. Utbildning för språklig och kulturell mångfald. Utbildningsdepartementet [Different Origins-Community in Sweden. Education for Linguistic Cultural Diversity]. Statens offentliga utredningar 1983:57. Stockholm: Utbildningsdepartementet.

Spotti, Massimiliano, and Jan Blommaert. 2017. Bilingualism, multilingualism, globalization and superdiversity: Toward sociolinguistic repertoires. In The Oxford Handbook of Language and Society. Edited by Ofelia Garcia, Nelson Flores and Massimiliano Spotti. New York: Oxford University Press, pp. 1-20. [CrossRef]

Steinmayr, Ricarda, Anne F. Weidinger, Malte Schwinger, and Birgit Spinath. 2019. The Importance of Students' Motivation for Their Academic Achievement-Replicating and Extending Previous Findings. Frontiers in Psychology 10: 1730-55. [CrossRef] [PubMed]

Stroud, Christopher. 2004. Halvspråkighet och rinkebysvenska som språkideologiska begrepp. In Svenska Som Andraspråk: $i$ Forskning, Undervisning och Samhälle. Edited by Kenneth Hyltenstam and Inger Lindberg. Lund: Studentlitteratur, pp. 329-357.

Swedish Research Council. 2011. Good Research Practice. Stockholm: Vetenskapsrådet. ISBN 978-91-7307-354-7. Available online: https:/ / www.vr.se/download/18.5639980c162791bbfe697882/1555334908942/Good-Research-Practice_VR_2017.pdf (accessed on 10 May 2021).

The Douglas Fir Group. 2016. A Transdisciplinary Framework for SLA in a Multilingual World. The Modern Language Journal 100: 19-47. [CrossRef]

Thomas, Nathan, and Christopher Osment. 2019. Building on Dewaele's (2018) L1 versus LX Dichotomy: The Language-Usage-Identity State Model. Applied Linguistics 1-7. [CrossRef]

Thompson, Amy. 2020. My many selves are still me: Motivation and multilingualism. Second Language Learning and Teaching 10: 159-76. [CrossRef]

Utbildningsdepartementet [Ministry of Education and Research]. 2010. Skollagen, SFS2010:800 [The Swedish Education Act, SFS 2010:800]. Stockholm: Utbildningsdepartementet.

Vogel, Sara, and Ofelia Garcia. 2017. Translanguaging. Oxford Research Encyclopedia of Education 2-21. [CrossRef]

Watt, Dominic, and Carmen Llamas. 2014. Language, Border and Identity. Edinburgh: Edinburgh University Press.

Wodak, Ruth, Rudolph De Cillia, Martin Reisigl, and Karen Liebhart. 2009. The Discursive Construction of National Identity. Edinburg: Edinburg University Press. 